\title{
Effects of probiotics on the improvement and regulation of intestinal barrier dysfunction and immune imbalance in intra-abdominal infections (Review)
}

\author{
SHUANGFENG TANG ${ }^{1-3^{*}}$, JIAYUE LIU ${ }^{1-3 *}$, CAIMING XU ${ }^{1-3}$, \\ DONG SHANG ${ }^{1-3}$, HAILONG CHEN ${ }^{1-3}$ and GUIXIN ZHANG ${ }^{1-3}$ \\ ${ }^{1}$ Laboratory of Integrative Medicine, The First Affiliated Hospital of Dalian Medical University, \\ Dalian, Liaoning 116011; ${ }^{2}$ Institute (College) of Integrative Medicine, Dalian Medical University, \\ Dalian, Liaoning 116044; ${ }^{3}$ Department of General Surgery, Pancreatic-Biliary Center, \\ The First Affiliated Hospital of Dalian Medical University, Dalian, Liaoning 116011, P.R. China
}

Received August 25, 2021; Accepted November 16, 2021

DOI: 10.3892/ijfn.2021.22

\begin{abstract}
Intra-abdominal infections (IAIs) are one of the most common critical diseases in clinical practice, with high morbidity and mortality rates. A variety of abdominal diseases can lead to abdominal infection, such as acute appendicitis, acute cholecystitis, various causes of gastrointestinal perforation, post-operative complications and trauma. It has been demonstrated that probiotics are of utmost significance in improving the treatment and prognosis of patients with IAIs. Probiotics play a beneficial role in the host's metabolism, immunity and nervous system by interacting with the host microorganisms, preventing the colonization of pathogens, improving intestinal barrier function, regulating immune function and producing related metabolites. The aim of the present review article was to discuss and summarize the regulatory effect of probiotics on intestinal barrier dysfunction and immunological imbalance in IAIs, in order to provide a foundation for the development of novel therapeutic approaches and disease prevention measures.
\end{abstract}

\section{Contents}

1. Introduction

2. Literature search strategy

3. Mechanisms of action of probiotics

Correspondence to: Professor Guixin Zhang, Laboratory of Integrative Medicine, The First Affiliated Hospital of Dalian Medical University, 222 Zhongshan Road, Dalian, Liaoning 116011, P.R. China E-mail: zgx0109@yeah.net

*Contributed equally

Key words: probiotics, intra-abdominal infections, intestinal barrier dysfunction, immune imbalance, antibiotics, bacterial translocation
4. Safety of the use of probiotics in intra-abdominal infection 5. Conclusions and future perspectives

\section{Introduction}

As one of the most common and severe acute abdomen diseases, intra-abdominal infections (IAIs) have become the main factor for the high mortality rate in diverse and complicated refractory disease (1). IAIs are mainly associated with abdominal traumatic surgery in the form of post-operative complications (2). The mortality rate from complicated intra-abdominal infections (CIAIs) varies between different countries and regions and ranges from $3-42 \%$ (3). In addition, the associated morbidity also exhibits an increasing trend. A previous multinational observational cohort study demonstrated that secondary peritonitis accounted for the vast majority of cases (68.4\%), followed by biliary tract infection (12.2\%), intra-abdominal abscess (6.9\%) and pancreatic infection (6.3\%) (4). IAI is a risk prognostic factor for complications of these diseases, and despite advances in treatment over the last few decades, the morbidity and mortality remain at high levels.

The definition of IAI is a general term for a class of diseases and represents a wide array of pathological conditions, including cholecystitis, pancreatitis, appendicitis, diverticulitis, and abdominal abscess and sepsis (5). Classified by its severity, IAI can be divided into two categories as follows: i) Uncomplicated intra-abdominal infection, which emerges in a single organ and is accompanied by mild symptoms; this can be treated using antibiotics therapy; and ii) CIAI, which not only affects the hollow organs, but also penetrates the pathological organs to reach the peritoneum (6), resulting in secondary peritonitis and even in severe abdominal abscess. Of note, peritonitis is typical of CIAI, and is mainly divided into primary and secondary peritonitis (Fig. 1). Moreover, CIAI can be further categorized into two types: Community CIAI that may be severe and occurring in the community, and hospital CIAI, which is also termed healthcare-acquired 
CIAI, usually occurring in patients who were hospitalized or who were admitted to other medical care institutions; the latter type is more common than the former (7), particularly as regards post-operative infections. IAI is a severe post-operative complication, which can lead to systemic inflammatory response syndrome, sepsis and even in multiple organ dysfunction syndrome. It induces pseudoaneurysm, sepsis and septic shock, which not only exacerbate patient suffering, but also lengthen hospital duration and increase medical costs; in addition, IAIs decreases the quality of life of patients and may even result in mortality (8).

Probiotics are live bacteria that, when consumed, modify the gut microbial flora and provide the host with health benefits (9). The use of probiotics has been examined in inflammatory bowel disease, irritable bowel syndrome and antibiotic-associated diarrhea (10-12). In the present review article, the current literature on the use of probiotic therapy in the treatment of IAIs is summarized.

\section{Literature search strategy}

The following electronic databases were used to search potentially relevant studies: PubMed (1995 to October, 2021), China National Knowledge Infrastructure (1995 to October, 2021) and Wan Fang Data (1995 to October, 2021).

The key words used included probiotics, intra-abdominal infections, intestinal barrier dysfunction (IBD), immune imbalance, mechanism, source control, antibiotics, bacterial translocation and intestinal mucosal permeability.

\section{Mechanisms of action of probiotics}

As is already known, there is a collection of microorganisms in nature. For the most part, this collection of microorganisms and bacteria has a negative impact on the daily life of humans. However, decades of research have revealed that bacteria, which is a subset of microorganisms that also includes viruses, fungi and other protists, plays a critical and useful role in the human body. All these microbes combine to form a chemical that some researchers have termed the microbiota. The microbiota can be found in a variety of tissues, including the mouth cavity, gastrointestinal tract, nasal cavity, and others. In particular, $\sim 80 \%$ of the normal microbiota is concentrate in the gut (13). It has been reported that almost 1,014 bacteria are present in adult intestinal cells, which is 10 -fold larger than the amount present in normal cells in the human body (14). Consequently, some researchers have even indicated that the intestinal microbiota is one of the organs in the human body (15).

The positive bacterial component is constituted by probiotics. Probiotics are microorganisms that may be of net benefit to humans when consumed. The administration of sufficient doses of probiotics, which are defined as live microorganisms, primarily modifies the balance of the intestinal microflora of the host (16). Probiotics are live microorganisms that can alter the intestinal microbial flora when ingested, and confer beneficial health effects to the host. Their use has been studied in various gastrointestinal conditions, including inflammatory bowel disease, irritable bowel syndrome and antibiotic-associated diarrhea. Metchnikff, who worked at the Pasteur Institute at the turn of the century, was the first to bring forth the hypothesis that individuals could benefit from the consumption of fermented milk (17). As a result, the World Health Organization (WHO) and the United Nations Food and Agriculture Organization (FAO) designated it as a food-grade ingredient used in dairy products that would promote the host's health. In one of his articles from 1954, Vergin (18) discussed the mechanisms thorough which antibiotics damage the healthy gut microorganisms. Since then, the general comprehension of probiotics and related applications have become increasingly thorough, and further in-depth research has been conducted.

Probiotics are currently categorized into three groups: Lactobacilli,Bifidobacteria, and Gram-positive cocci, including certain yeasts and enzymes. However, depending on the source and mode of action, they are divided into symbiotic bacteria, native bacteria and fungi (19). Lactobacilli, Bifidobacterium, butyric acid-producing bacteria, Escherichia coli (E. coli), Streptococcus thermophilus and other bacteria are all considered to be applicable to the human body on a global scale. Currently, the mechanisms of action of probiotics, such as lactic acid bacteria, Bifidobacteria and yeast, are relatively well understood, and previous research has been performed in this field. For instance, it has been demonstrated that the combined use of Lactobacillus rhamnosus GG (LGG) with conventional antibiotic therapy reduces bacterial translocation, preventing bile duct obstruction (20). Lactobacillus strains have also been shown to significantly enhance the phagocytic activity of macrophages (21). In recurrent respiratory tract infections, the abundance of Bifidobacterium has been shown to be reduced (21).

Probiotics mainly restore the balance of the flora of the body via a mechanism termed the flora-host interaction (22). A multitude of biological reactions are also involved in this process. Probiotics have been shown to function via a variety of mechanisms. For example, through competitive inhibition, they can limit the ability of pathogens to adhere to and colonize mucous membranes. Some probiotics secrete proteases which aid in the breakdown of toxins. Probiotics have also been shown to alter host immune functions by inhibiting the release of pro-inflammatory cytokines by T-cells, and some probiotic strains have been shown to inhibit mitogen-induced lymphocyte proliferation in vitro in a similar manner to dexamethasone (23). In addition, probiotic bacteria exert a potential protective effect against enteropathogens through various mechanisms, including the production of antimicrobial compounds, the reduction of pathogenic bacterial adhesion and the competition for host cell binding sites. The probiotics principle can be characterized by the following mechanisms: Immunoregulation, competitive inhibition, signal transduction and metabolic alterations are all examples of barrier function (24-27). Immunoregulation can be further divided into innate and specific immunity (25). It can also inhibit the adhesion and colonization of pathogens through competitive inhibition (28). The oral administration of probiotics can increase the number of IgA cells in the intestinal lamina propria (29). Moreover, probiotics can also induce IgA circulation and significantly increase the activity of macrophages distal to the gastrointestinal tract (30).

Regulatory effects of probiotics on the disruption of the bacterial flora in IAIs. Similar to the endogenous microbiota, 


\section{CLASSIFICATION OF PERITONITIS}

\begin{tabular}{|c|c|c|}
\hline Involved scope & \multicolumn{2}{|l|}{ Pathogenesis } \\
\hline $\begin{array}{l}\text { Diffuse peritonitis } \\
\text { Localized peritonitis }\end{array}$ & $\begin{array}{l}\text { Primary peritonitis (spontaneous peritonitis) } \\
\text {-Female: The ascending bacteria of female } \\
\text { reproductive tract spread into abdominal cavity } \\
\text {-Infants and children: have decreased resistance } \\
\text {-Adults: caused by cirrhosis complicated with } \\
\text { ascites }\end{array}$ & $\begin{array}{l}\text { hemolytic streptococcus } \\
\text { Streptococcus pneumoniae } \\
\text { Escherichia coli }\end{array}$ \\
\hline Clinical course & $\begin{array}{l}\text {-Ruptured abdominal viscera } \\
\text {-Acute inflammation }\end{array}$ & $\begin{array}{l}\text { 谯Escherichia coli } \\
\text { (most common) }\end{array}$ \\
\hline $\begin{array}{l}\text { Acute peritonitis } \\
\text { Chronic peritonitis }\end{array}$ & $\begin{array}{l}\text { - Necrotic bowel } \\
\text {-Abdominal surgery } \\
\text {-Infection of female reproductive organs }\end{array}$ & 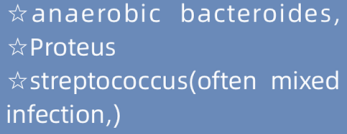 \\
\hline
\end{tabular}

Figure 1. Classification of peritonitis. Peritonitis was classified in terms of the scope, clinical course and pathogenesis.

probiotics can improve mucosal barrier function, limiting the ability of viral particles to cross the barrier, thus maintaining this physical barrier during viral disease (31). The adhesion of viruses to the mucosal surface is the first step in infection. Extracellular polysaccharides produced by lactic acid bacteria have been shown to interfere effectively with this step, as for example adenoviruses (32). However, the most effective antiviral effect of probiotics is the regulation of the immune system. Selected probiotics have been reported to increase natural killer cell activity and cytotoxic activity (33). In addition, responses to antiviral cytokines, such as interferon $\gamma$ (IFN- $\gamma$ ), interleukin (IL)-2, IL-12 and IL-18, as well as improved antibody responses have been reported with the use of probiotics (34). It is thus possible that several of these mechanisms and others operate in parallel and/or consecutively.

The incidence of IAIs, CIAIs in particular, is one of the most common reasons for the increased health costs observed $\$ 25,000$ per case in the USA (35). The treatment regimen for CIAIs, according to the most recent World Society of Emergency Surgery (WSES) management guideline (3), is simply a combination of various antibiotics. It is also for this reason that, as a result of the overuse of antibiotics, resistance to medication is becoming a major concern for all clinicians and patients (36). Thus, it is necessary to search for a promising prevention and treatment strategy for CIAIs with limited side-effects. Probiotics appear to meet this requirement. As previously indicated by a clinical questionnaire in 2011, a number of gastroenterologists and surgeons in the UK have recommend the daily oral use of probiotics to their patients; in some cases probiotics have been directly prescribed (37). In a previous systematic review and meta-analysis of randomized controlled trials, 1,354 patients were administered probiotics in the treatment group, while 1,369 patients were administered the placebo in the control group. The outcome manifested that the use of probiotics decreased the risk of developing IAIs and related complications post-operatively (38). Additionally, it has been demonstrated that probiotics can reduce the levels of pro-inflammatory cytokines in rodents with post-infectious irritable bowel syndrome (39). As already aforementioned, IAIs are associated with the emergence of bacterial translocation. However, bacterial translocation is caused by IBD. The intestinal tract serves as a repository for bacteria and endotoxins, and the colonic mucosal epithelium is tightly connected to this tract, which provides a strong barrier function, so that bacteria (or endotoxins) cannot easily transfer to other normal sterile tissues through the barrier (40). Probiotics can boost the expression of transmembrane binding protein (occludin) and IgA, allowing the barrier function to be improved and bacterial translocation to be reduced (41). Probiotics perform a similar coordinating function by exerting immunomodulatory effects. In animal models, oral Lactobacillus strains have been shown to activate the mucosal immune system and to affect the distal intestinal mucosa (42). A previous study discussed the role of probiotics in the prevention and treatment of intestinal infections (25).

Intestinal mucosal barrier (IMB) function of probiotics in IAIs. Intestinal barrier function (IBF) is one of the most essential barriers of the human body. Intestinal epithelial cells (IECs) separate the inner and outer intestinal cavity so that bacteria, endotoxins or other related pathogens, which may cause a variety of infections, are unable to move across the IMB to other tissues outside the intestinal lumen, preventing the body from invasion by endogenous microorganisms and their toxins (43). IBD can accelerate endotoxin and bacterial translocation. IBD is caused by a number of factors, such as inflammation, stress, trauma, hypovolemia and ischemia-reperfusion injury. In particular, infection, which is caused by the invasion of a pathogen into the body, plays a major role in IBD. Infection can lead to the activation and release of inflammatory factors in human organs, and neutrophil aggregation and adhesion result in damage to the intestinal mucosa. This can subsequently reduce intestinal mucosa permeability, thus lead to a series of pathological processes (44). Thus, the intestinal tract is not only the initiator of infection, but also the 'victim' of infection, and both play a causal role. Similarly, the occurrence of abdominal infection aggravates IBD, and the further aggravation of IBD further increases the occurrence of abdominal infections, forming a vicious cycle. The core of 
Table I. Studies evaluating the efficacy of probiotics in intra-abdominal infections.

\begin{tabular}{|c|c|c|c|c|c|c|}
\hline Authors & $\begin{array}{l}\text { No. of } \\
\text { subjects }\end{array}$ & Methods & $\begin{array}{l}\text { Study } \\
\text { duration }\end{array}$ & Patients & Year & (Refs.) \\
\hline Poonyam et al & 100 & $\begin{array}{l}\text { Double-blind randomized } \\
\text { placebo-controlled }\end{array}$ & $\geq 4$ weeks & Aged $\geq 18$ years (with non-ulcer dyspepsia) & 2019 & $(77)$ \\
\hline Çekin et al & 159 & $\begin{array}{l}\text { Randomized placebo- } \\
\text { controlled }\end{array}$ & 2 weeks & $\begin{array}{l}\text { Patients with } H . \text { pylori infection receiving } \\
\text { sequential } H . \text { pylori eradication therapy }\end{array}$ & 2017 & $(78)$ \\
\hline Shukla et al & 46 & $\begin{array}{l}\text { Prospective randomized } \\
\text { controlled trials }\end{array}$ & 12 weeks & $\begin{array}{l}\text { Patients were children aged } 6-20 \text { years } \\
\text { with diagnosed IBD }\end{array}$ & 2016 & $(26)$ \\
\hline Pande et al & 110 & $\begin{array}{l}\text { Double-blind, randomized- } \\
\text { controlled trials }\end{array}$ & 6 months & Consecutive patients with cirrhosis & 2012 & $(79)$ \\
\hline Diepenhorst et al & 30 & $\begin{array}{l}\text { Prospective randomized } \\
\text { controlled trials }\end{array}$ & 4 weeks & $\begin{array}{l}\text { Patients scheduled for a PPPD with } \\
\text { curative intent for a periampullary } \\
\text { or ampullary pancreatic malignancy }\end{array}$ & 2011 & $(80)$ \\
\hline
\end{tabular}

IBD, inflammatory bowel disease; PPPD, pylorus-preserving pancreaticoduodenectomy.

the IBF is IMB, which includes a mechanical barrier, chemical barrier, immune barrier and biological barrier (Fig. 2).

The intestinal barrier can prevent harmful substances in the intestinal cavity, such as pathogens and toxins, from entering other tissues and organs in the body and blood circulation through the intestinal mucosa. It represents a direct physical barrier for the host. Injuries to the intestinal barrier increase intestinal permeability to bacteria and their metabolites (45). The IMB is responsible for the majority of negative effects on IBF. When the IMB is compromised, bacteria and their derivatives in the intestines can break through and enter the bloodstream, causing bacteria or endotoxins to be transferred to other organs, thus promoting the spread of enterogenous illness (46). A number of studies have evaluated the efficacy of probiotics in IAIs (Table I). For example, some lactic acid bacteria and Bifidobacterium can upregulate the expression of tight junction proteins, improving intestinal integrity and protecting the IMB $(47,48)$. Miele et al $(48)$ demonstrated that damage to the tight junctions of IECs may lead to increased intestinal permeability, leading to the transposition of a large number of bacteria and bacterial endotoxins into the blood circulation. Probiotics can help prevent the invasion of pathogenic bacteria, forming a microbial membrane with intestinal mucosal epithelial cells, and competitively inhibiting the adhesion and colonization of pathogenic bacteria (47).

Immune regulatory mechanisms of probiotics in IAIs. The interaction with IECs and the generation of certain immune regulatory factors to increase the body's immune function and manufacture immunoglobulin to resist harmful microorganisms represent the regulatory effects of the immune system. When activated by antigens, macrophages, B lymphocytes and natural killer cells initiate an immunological response, stimulating the intestinal mucosa to release anti-inflammatory cytokines, increasing intestinal immunological performance and enhancing immunological barrier function (49). Some probiotics can boost phagocytic or natural killer cell activity and interact with dendritic cells directly. Bharwani et al treated mice with oral Lactobacillus rhamnosus (JB-1) for 28 days, and the results revealed that treatment with JB-1 increased $\underline{\mathrm{IL}-10^{+}}$ regulatory T-cells and reduced the activation of stress-related dendritic cells, affecting the regulation of stress on immunity (50). Furthermore, to limit inflammation, Bifidobacterium relies on T-cell control, and it can significantly reduce the inflammatory phenotype and histopathology produced by cytotoxic T-lymphocyte antigen 4 (CTLA-4) antibodies (50).

Regulation of the gut barrier by probiotic metabolites in IAIs. Probiotics lead to the formation of secondary metabolites, such as bacteriocins, extracellular vesicles, short fatty acids chain, indole and extracellular proteins (secreted proteins). Bacteriocins are a class of ribosomally synthesized antimicrobial peptides produced by bacteria $(51,52)$. Bacteriocins can function as colonizing peptides of certain intestinal micro-organisms, promoting these bacteria to obtain a competitive advantage over other strains and to thus occupy established niches in the intestines. Alternatively, bacteriocins can function as 'killing' peptides, since they can interfere with the growth of pathogens (particularly Gram-negative bacteria) by penetrating the inner membrane or disrupting cell wall synthesis (53). Extracellular vesicles are involved in bacteria-host communications and in the maintenance of the gut homeostasis. It has been reported that the oral application of Akkermansia muciniphila-derived extracellular vesicles can alleviate dextran sulfate sodium-induced colitis by preventing inflammatory cell infiltration into the colon wall and alterations in colon length (54). Short-chain fatty acids, which comprise mainly butyrate, propionate and acetate, are metabolites secreted by intestinal microbiota from undigested dietary carbohydrates and proteins (55). As butyrate, among all short-chain fatty acids, is the preferred source of energy for colonic epithelial cells, the association between butyrate and the intestinal epithelial barrier has been previously studied (56). Butyrate can promote gut epithelium $\mathrm{O}_{2}$ consumption, resulting in the stabilization of hypoxia-inducible factor (HIF) and can increase the expression of barrier-protective HIF target genes, connecting microbes and epithelial barriers (57). Indole is usually produced by bacteria that contain tryptophanase and has been reported to function as an intestinal symbiotic bacteria 


\section{MECHANISM OF PROBIOTICS IN INTRA-ABDOMINAL INFECTIONS}

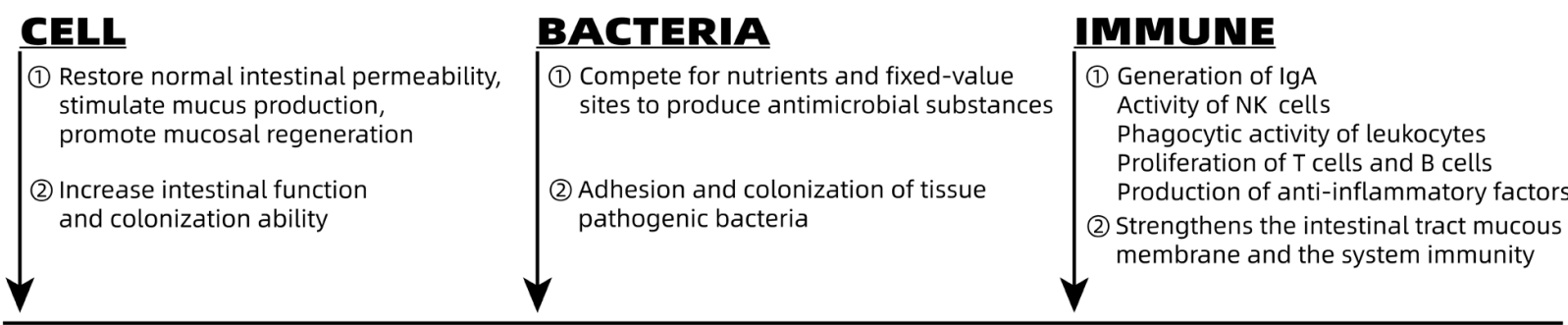

Effectively resist pathogens, regulate the balance of intestinal flora, maintain intestinal mucosal barrier function.

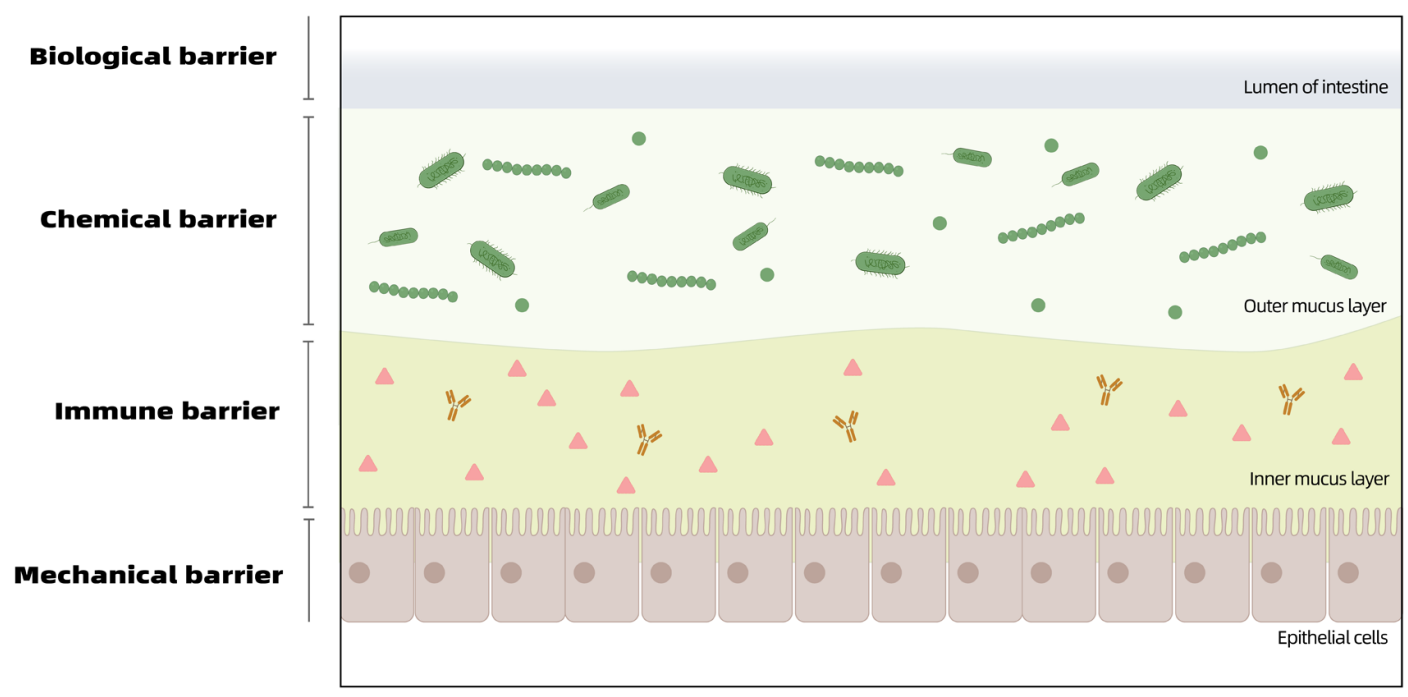

Figure 2. Mechanisms of action of probiotics in intra-abdominal infections. The top panel illustrates the cell-, bacteria- and immune-related mechanisms of probiotics. The bottom panel illustrates the sections of the intestinal mucosal barrier. NK cells, natural killer cells.

signal $(58,59)$. It has been demonstrated that indole produced by symbiotic $E$. coli can inhibit the chemotaxis of pathogenic E. coli. E. coli-secreted indole can also inhibit the attachment of pathogens to the epithelium by increasing the expression of genes involved in intestinal epithelial function, such as actin cytoskeleton, adhesion junctions and tight junctions (60). The Lactiplantibacillus plantarum BMCM12 secretes extracellular proteins and considerably reduces the adhesion of microbes or strengthens the gut barrier. It has been shown that two proteins secreted by $p 40, p 75$ and $L G G$ improve IEC homeostasis. Moreover, $p 40$ and $p 75$ maintain gut homeostasis by activating the EGFR/PIK3/Akt signaling pathway. It has been confirmed that probiotic-secreted proteins are involved in the host and symbiotic bacterial association (61).

These secondary metabolites can protect the gut epithelial barrier, while integrating with certain antimicrobial peptides, instantly enhancing mucus secretion via goblet cells and promoting the tight junction protein expression. They thus participate in the metabolism of human nutrients.

\section{Safety of the use of probiotics in intra-abdominal infec- tion}

Approximately 230 million surgical procedures are performed worldwide each year. Some can lead to complications post-surgery, including surgical site infections, urinary tract infections, pneumonia and sepsis. Standard practice is prophylactic antibiotic treatment; however, this is complicated by the increase in antibiotic resistance. A recent network meta-analysis of 2,952 patients undergoing abdominal surgery in 31 studies revealed a beneficial effect of synbiotics on surgical site infection (62). In that meta-analysis, it was found that synbiotics (successful trials focused on Lactiplantibacillus plantarum, Lacticaseibacillus casei and Bifidobacterium breve combined with galacto-oligosaccharides) were the most effective interventions for reducing pneumonia, urinary tract infections, sepsis, hospital duration and antibiotic use, whereas they had no effect on mortality (62). It was concluded that surgeons should consider the use of synbiotics as an adjuvant treatment for the prevention of post-operative complications (54). Another meta-analysis documented similar effects (63), although it was concluded that these observations should be treated with caution due to possible publication bias. In a recent randomized controlled clinical trial, in which 55 patients who underwent liver transplants received four probiotics or polylactic acid-placebo treatments prior to the scheduled transplantation, it was shown that at 90 days following the intervention, the infection rate was significantly lower in the patients receiving the probiotics compared with the control group (5 vs. 48\%, P=0.002) (64). In 
addition, in another randomized controlled clinical trial with 18 patients with head and neck cancer, no symbiotic effects of Lacticaseibacillus paracase, Bifidobacterium lactis, Lactobacillus acidophilus and Lactobacillus plus fructooligosaccharides were observed compared with the 18 placebo controls (65). Several clinical trials on human milk oligosaccharides (HMOs) have been registered, and HMOs may well represent a novel trend in prebiotics (66-68). Chemically defined metabolites or cell wall compounds released by probiotics may also become more important in the future (69). Probiotics may affect the gut-brain axis, with implications for patients with irritable bowel syndrome, mood disorders and anxiety (70).

\section{Conclusions and future perspectives}

In recent years, studies have demonstrated that the intestinal flora of patients with abdominal cavity infections exhibits certain dysfunctions, and the resulting intestinal microecological imbalance and the impaired IMB function may be the starting point of the inflammatory reaction of abdominal cavity infection. When the intestinal flora is unbalanced, the IMB function is impaired, and the impaired IMB function is the most important link for the occurrence of intestinal inflammatory reactions and abdominal infections. As a result, preserving the intestinal microecological balance is crucial in the treatment of abdominal infections $(15,42,47,71)$. It has been shown that $\mathrm{H}_{2} \mathrm{O}_{2}$, bacteriocin and biosurfactant secreted by Lactobacillus can kill pathogenic microorganisms, so as to further control the inflammatory response and enhance the therapeutic effect (47).

The metabolites of probiotics play a crucial role in regulating host-disease interactions. Extracellular polysaccharide (EPSCG11) from Lactobacillus plantarum BGCG11 has been shown to alleviate inflammatory pain in rats, reducing the expression of pro-inflammatory factor, and increasing that of anti-inflammatory factors (IL-10 and IL-6), thus exerting potent anti-hyperalgesic and anti-edema effects (72). Therefore, it can be concluded that the application of probiotics for the clinical treatment of abdominal cavity infections may aid in the suppression of the inflammatory response and in relieving associated pain or discomfort.

Despite reports of microbial research in high-impact scientific journals (73-76), a broad definition of probiotics should be avoided. In the case that a probiotic is found to exert a medical effect, it should be noted that this effect is associated with specific strains or specific prebiotics, providing specific health effects in a specific patient or in a specific population. Although this statement is trivial, it is still difficult to distill these positive conclusions from the complex and sometimes contradictory research literature.

In conclusion, probiotics and their metabolites may improve the prognosis of IAIs by regulating IBF, immune regulation and dysbacteriosis. However, further large-sample, multi-center clinical trials are required to further explore the use of probiotics in the treatment of IAIs.

\section{Acknowledgements}

Not applicable.

\section{Funding}

The present study was supported by the key Discipline of Liaoning Traditional Chinese Medicine Clinical Ability Promote Construction Project (grant no. 2019JH-8), the development Guidance Plan Projects in Liaoning Province (grant no. 10300028) and the National Science Foundation of China Project (grant no. 82174136).

\section{Availability of data and materials}

Not applicable.

\section{Authors' contributions}

ST and JL conceived the review and drafted the manuscript. CX was responsible for the preparation of the figures and the literature search. DS and HC revised, edited and finalized the manuscript for submission. GZ reviewed the manuscript. All authors have read and approved the final manuscript. Data authentication is not applicable.

\section{Ethics approval and consent to participate}

Not applicable.

\section{Patient consent for publication}

Not applicable.

\section{Competing interests}

The authors declare that they have no competing interests.

\section{References}

1. Shirah GR and O'Neill PJ: Intra-abdominal Infections. Surg Clin North Am 94: 1319-1333, 2014.

2. Mazuski JE, Tessier JM, May AK, Sawyer RG, Nadler EP, Rosengart MR, Chang PK, O'Neill PJ, Mollen KP, Huston JM, et al: The Surgical Infection Society Revised Guidelines on the Management of Intra-Abdominal Infection. Surg Infect (Larchmt) 18: $1-76,2017$

3. Lalisang TJM, Usman N, Hendrawidjaya I, Handaya AY, Nasution S, Saunar RY, Loho T, Karuniawati A, Moenadjat Y and Widyahening IS: Clinical Practice Guidelines in Complicated Intra-Abdominal Infection 2018: An Indonesian Perspective. Surg Infect (Larchmt) 20: 83-90, 2019.

4. Blot S, Antonelli M, Arvaniti K, Blot K, Creagh-Brown B, de Lange D, De Waele J, Deschepper M, Dikmen Y, Dimopoulos G, et al; Abdominal Sepsis Study (AbSeS) group on behalf of the Trials Group of the European Society of Intensive Care Medicine: Epidemiology of intra-abdominal infection and sepsis in critically ill patients: 'AbSeS', a multinational observational cohort study and ESICM Trials Group Project. Intensive Care Med 45: 1703-1717, 2019.

5. Menichetti F and Sganga G: Definition and classification of intra-abdominal infections. J Chemother 21 (Suppl 1): 3-4, 2009.

6. Zhang J, Di Y, Wang Z and Liu C: Re-Thinking the Definition of Complicated Intra-Abdominal Infection. Surg Infect (Larchmt) 18: 374, 2017.

7. Pieracci FM and Barie PS: Management of severe sepsis of abdominal origin. Scand J Surg 96: 184-196, 2007.

8. Allegranzi B, Zayed B, Bischoff P, Kubilay NZ, de Jonge S, de Vries F, Gomes SM, Gans S, Wallert ED, Wu X, et al; WHO Guidelines Development Group: New WHO recommendations on intraoperative and postoperative measures for surgical site infection prevention: An evidence-based global perspective. Lancet Infect Dis 16: e288-e303, 2016. 
9. Salminen S, Collado MC, Endo A, Hill C, Lebeer S, Quigley EMM, Sanders ME, Shamir R, Swann JR, Szajewska H and Vinderola G: The International Scientific Association of Probiotics and Prebiotics (ISAPP) consensus statement on the definition and scope of postbiotics. Nat Rev Gastroenterol Hepatol 18: 649-667, 2021.

10. Karban A: Effect of Probiotics on Inflammatory Bowel Diseases. J Inflam Bowel Dis Disorder 6 :e108, 2021.

11. Agamennone V, Krul CAM, Rijkers G and Kort R: A practical guide for probiotics applied to the case of antibiotic-associated diarrhea in The Netherlands. BMC Gastroenterol 18: 103, 2018.

12. Simon E, Călinoiu LF, Mitrea L and Vodnar DC: Probiotics, Prebiotics, and Synbiotics: Implications and Beneficial Effects against Irritable Bowel Syndrome. Nutrients 13: 2112, 2021.

13. Kundu P, Blacher E, Elinav E and Pettersson S: Our Gut Microbiome: The Evolving Inner Self. Cell 171: 1481-1493, 2017.

14. Sommer F and Bäckhed F: The gut microbiota - masters of host development and physiology. Nat Rev Microbiol 11: 227-238, 2013.

15. Sánchez B, Delgado S, Blanco-Míguez A, Lourenço A Gueimonde $\mathrm{M}$ and Margolles A: Probiotics, gut microbiota, and their influence on host health and disease. Mol Nutr Food Res 61: 1600240, 2017.

16. Pan SJ, Kuo CH, Lam KP, Chu YT, Wang WL and Hung $\mathrm{CH}$ Probiotics and allergy in children - an update review. Pediatr Allergy Immunol 21: e659-e666, 2010.

17. Vanderhoof JA and Young RJ: Pediatric applications of probiotics Gastroenterol Clin North Am 34: 451-463, viii-ix, 2005

18. Vergin F: Antibiotics and probiotics. Hippokrates 25: 116-119, 1954 (In Undetermined language).

19. Sanders ME: Overview of Functional Foods: Emphasis on Probiotic Bacteria. Int Dairy J 8: 341-347, 1998.

20. Celikkaya ME, Akcora B, Hakverdi S, Ozer B, Ulutas KT and Duran N: Effects of Probiotic Use on Bacterial Translocation in Created Rat Models with Biliary Obstructions. Eurasian J Med 51: 106-111, 2019.

21. Li L, Wang F, Liu Y and Gu F: Intestinal microbiota dysbiosis in children with recurrent respiratory tract infections. Microb Pathog 136: 103709, 2019.

22. Maslowski KM: Metabolism at the centre of the host-microbe relationship. Clin Exp Immunol 197: 193-204, 2019.

23. Liu Q, Tian H, Kang Y, Tian Y, Li L, Kang X, Yang H, Wang Y, Tian J, Zhang F, et al: Probiotics alleviate autoimmune hepatitis in mice through modulation of gut microbiota and intestinal permeability. J Nutr Biochem 98: 108863, 2021.

24. Narula N and Marshall JK: Role of probiotics in management of diverticular disease. J Gastroenterol Hepatol 25: 1827-1830, 2010

25. Iqbal Z, Ahmed S, Tabassum N, Bhattacharya R and Bose D: Role of probiotics in prevention and treatment of enteric infections: A comprehensive review. 3 Biotech 11: 242, 2021

26. Shukla A, Gaur P and Aggarwal A: Effect of probiotics on clinical and immune parameters in enthesitis-related arthritis category of juvenile idiopathic arthritis. Clin Exp Immunol 185 301-308, 2016

27. Gupta V and Garg R: Probiotics. Indian J Med Microbiol 27 202-209, 2009

28. Monteagudo-Mera A,Rastall RA, Gibson GR,Charalampopoulos D and Chatzifragkou A: Adhesion mechanisms mediated by probiotics and prebiotics and their potential impact on human health. Appl Microbiol Biotechnol 103: 6463-6472, 2019.

29. Yurong Y, Ruiping S, Shimin Z and Yibao J: Effect of probiotics on intestinal mucosal immunity and ultrastructure of cecal tonsils of chickens. Arch Anim Nutr 59: 237-246, 2005.

30. Zeng W, Shen J, Bo T, Peng L, Xu H, Nasser MI, Zhuang Q and Zhao M: Cutting Edge: Probiotics and Fecal Microbiota Transplantation in Immunomodulation. J Immunol Res 2019: 1603758, 2019.

31. Bron PA, Kleerebezem M, Brummer R-J, Cani PD, Mercenier A, MacDonald TT, Garcia-Ródenas CL and Wells JM: Can probiotics modulate human disease by impacting intestinal barrier function? Br J Nutr 117: 93-107, 2017.

32. Biliavska L, Pankivska Y, Povnitsa O and Zagorodnya S: Antiviral Activity of Exopolysaccharides Produced by Lactic Acid Bacteria of the Genera Pediococcus, Leuconostoc and Lactobacillus against Human Adenovirus Type 5. Medicina (Kaunas) 55: 519, 2019

33. Miller LE, Lehtoranta L and Lehtinen MJ: Short-term probiotic supplementation enhances cellular immune function in healthy elderly: Systematic review and meta-analysis of controlled studies. Nutr Res 64: 1-8, 2019.
34. Lehtoranta L, Latvala S and Lehtinen MJ: Role of Probiotics in Stimulating the Immune System in Viral Respiratory Tract Infections: A Narrative Review. Nutrients 12: 3163, 2020.

35. Lytvyn L, Quach K, Banfield L, Johnston BC and Mertz D: Probiotics and synbiotics for the prevention of postoperative infections following abdominal surgery: A systematic review and meta-analysis of randomized controlled trials. J Hosp Infect 92: 130-139, 2016.

36. Adámková V: The role of new antibiotics in intra-abdominal infections in the era of multi-resistant bacteria. Rozhl Chir 98: 145-151, 2019.

37. Cordina C, Shaikh I, Shrestha S and Camilleri-Brennan J: Probiotics in the management of gastrointestinal disease: Analysis of the attitudes and prescribing practices of gastroenterologists and surgeons. J Dig Dis 12: 489-496, 2011

38. Chowdhury AH, Adiamah A, Kushairi A, Varadhan KK, Krznaric Z, Kulkarni AD, Neal KR and Lobo DN: Perioperative Probiotics or Synbiotics in Adults Undergoing Elective Abdominal Surgery: A Systematic Review and Meta-analysis of Randomized Controlled Trials. Ann Surg 271: 1036-1047, 2020.

39. Hong KB, Seo H, Lee JS and Park Y: Effects of probiotic supplementation on post-infectious irritable bowel syndrome in rodent model. BMC Complement Altern Med 19: 195, 2019.

40. Liu Z, Qin H, Yang Z, Xia Y, Liu W, Yang J, Jiang Y, Zhang H, Yang Z, Wang Y, et al: Randomised clinical trial: The effects of perioperative probiotic treatment on barrier function and post-operative infectious complications in colorectal cancer surgery - a double-blind study. Aliment Pharmacol Ther 33: $50-63,2011$

41. Michail S and Abernathy F: Lactobacillus plantarum reduces the in vitro secretory response of intestinal epithelial cells to enteropathogenic Escherichia coli infection. J Pediatr Gastroenterol Nutr 35: 350-355, 2002

42. Paone P and Cani PD: Mucus barrier, mucins and gut microbiota: The expected slimy partners? Gut 69: 2232-2243, 2020.

43. Shen TY, Qin HL, Gao ZG, Fan XB, Hang XM and Jiang YQ: Influences of enteral nutrition combined with probiotics on gut microflora and barrier function of rats with abdominal infection. World J Gastroenterol 12: 4352-4358, 2006.

44. Tao Z, Hu FQ, Li CF, Zhang T, Cao BZ and Cui LQ: Effect of ulinastatin, a human urinary protease inhibitor, on heatstroke-induced apoptosis and inflammatory responses in rats. Exp Ther Med 13: 335-341, 2017.

45. Rohr MW, Narasimhulu CA, Rudeski-Rohr TA and Parthasarathy S: Negative Effects of a High-Fat Diet on Intestinal Permeability: A Review. Adv Nutr 11: 77-91, 2020.

46. Nagpal K, Minocha VR, Agrawal V and Kapur S: Evaluation of intestinal mucosal permeability function in patients with acute pancreatitis. Am J Surg 192: 24-28, 2006.

47. La Fata G, Weber P and Mohajeri MH: Probiotics and the Gut Immune System: Indirect Regulation. Probiotics Antimicrob Proteins 10: 11-21, 2018.

48. Miele L, Valenza V, La Torre G, Montalto M, Cammarota G, Ricci R, Mascianà R, Forgione A, Gabrieli ML, Perotti G, et al: Increased intestinal permeability and tight junction alterations in nonalcoholic fatty liver disease. Hepatology 49: 1877-1887, 2009.

49. Rose EC, Odle J, Blikslager AT and Ziegler AL: Probiotics, Prebiotics and Epithelial Tight Junctions: A Promising Approach to Modulate Intestinal Barrier Function. Int J Mol Sci 22: 6729, 2021.

50. Bharwani A, Mian MF, Surette MG, Bienenstock J and Forsythe P: Oral treatment with Lactobacillus rhamnosus attenuates behavioural deficits and immune changes in chronic social stress. BMC Med 15: 7, 2017.

51. Gillor O, Etzion A and Riley MA: The dual role of bacteriocins as anti- and probiotics. Appl Microbiol Biotechnol 81: 591-606, 2008.

52. Chikindas ML, Weeks R, Drider D, Chistyakov VA and Dicks LMT: Functions and emerging applications of bacteriocins. Curr Opin Biotechnol 49: 23-28, 2018.

53. Majeed H, Gillor O, Kerr B and Riley MA: Competitive interactions in Escherichia coli populations: The role of bacteriocins. ISME J 5: 71-81, 2011.

54. Kang CS, Ban M, Choi EJ, Moon HG, Jeon JS, Kim DK, Park SK, Jeon SG, Roh TY, Myung SJ, et al: Extracellular Vesicles Derived from Gut Microbiota, Especially Akkermansia muciniphila, Protect the Progression of Dextran Sulfate Sodium-Induced Colitis. PLoS One 8: e76520, 2013.

55. Hamer HM, Jonkers D, Venema K, Vanhoutvin S, Troost FJ and Brummer RJ: Review article: The role of butyrate on colonic function. Aliment Pharmacol Ther 27: 104-119, 2008. 
56. Donohoe DR, Garge N, Zhang X, Sun W, O'Connell TM, Bunger MK and Bultman SJ: The microbiome and butyrate regulate energy metabolism and autophagy in the mammalian colon. Cell Metab 13: 517-526, 2011.

57. Kelly CJ,Zheng L, Campbell EL, Saeedi B, Scholz CC, Bayless AJ, Wilson KE, Glover LE, Kominsky DJ, Magnuson A, et al: Crosstalk between Microbiota-Derived Short-Chain Fatty Acids and Intestinal Epithelial HIF Augments Tissue Barrier Function. Cell Host Microbe 17: 662-671, 2015.

58. Shimada Y, Kinoshita M, Harada K, Mizutani M, Masahata K, Kayama $\mathrm{H}$ and Takeda K: Commensal Bacteria-Dependent Indole Production Enhances Epithelial Barrier Function in the Colon. PLoS One 8: e80604, 2013.

59. Beaumont M, Neyrinck AM, Olivares M, Rodriguez J, de Rocca Serra A, Roumain M, Bindels LB, Cani PD, Evenepoel P, Muccioli GG, et al: The gut microbiota metabolite indole alleviates liver inflammation in mice. FASEB J 32: fj201800544, 2018.

60. Bansal T, Alaniz RC, Wood TK and Jayaraman A: The bacterial signal indole increases epithelial-cell tight-junction resistance and attenuates indicators of inflammation. Proc Natl Acad Sci USA 107: 228-233, 2010.

61. Liu Q, Yu Z, Tian F, Zhao J, Zhang H, Zhai Q and Chen W: Surface components and metabolites of probiotics for regulation of intestinal epithelial barrier. Microb Cell Fact 19: 23, 2020.

62. Kasatpibal N, Whitney JD, Saokaew S, Kengkla K, Heitkemper MM and Apisarnthanarak A: Effectiveness of Probiotic, Prebiotic, and Synbiotic Therapies in Reducing Postoperative Complications: A Systematic Review and Network Meta-analysis. Clin Infect Dis 64 (Suppl 2): S153-S160, 2017

63. Yang Z, Wu Q, Liu Y and Fan D: Effect of Perioperative Probiotics and Synbiotics on Postoperative Infections After Gastrointestinal Surgery: A Systematic Review With Meta-Analysis. JPEN J Parenter Enteral Nutr 41: 1051-1062, 2017.

64. Grąt M, Wronka KM, Lewandowski Z, Grąt K, Krasnodebski M, Stypułkowski J, Hołówko W, Masior Ł, Kosińska I, Wasilewicz M, et al: Effects of continuous use of probiotics before liver transplantation: A randomized, double-blind, placebo-controlled trial. Clin Nutr 36: 1530-1539, 2017.

65. Lages PC, Generoso SV and Correia MITD: Postoperative symbiotic in patients with head and neck cancer: A double-blind randomised trial. Br J Nutr 119: 190-195, 2018.

66. Sakanaka M, Gotoh A, Yoshida K, Odamaki T, Koguchi H, Xiao JZ, Kitaoka M and Katayama T: Varied Pathways of Infant Gut-Associated Bifidobacterium to Assimilate Human Milk Oligosaccharides: Prevalence of the Gene Set and Its Correlation with Bifidobacteria-Rich Microbiota Formation. Nutrients 12 71, 2019.

67. Bering SB: Human Milk Oligosaccharides to Prevent Gut Dysfunction and Necrotizing Enterocolitis in Preterm Neonates. Nutrients 10: 1461, 2018

68. Donovan SM and Comstock SS: Human Milk Oligosaccharides Influence Neonatal Mucosal and Systemic Immunity. Ann Nutr Metab 69 (Suppl 2): 42-51, 2016.
69. Aguilar-Toalá JE, Garcia-Varela R, Garcia HS, Mata-Haro V, González-Córdova AF, Vallejo-Cordoba B and HernándezMendoza A: Postbiotics: An evolving term within the functional foods field. Trends Food Sci Technol 75: 105-114, 2018.

70. Mörkl S, Butler MI, Holl A, Cryan JF and Dinan TG: Probiotics and the Microbiota-Gut-Brain Axis: Focus on Psychiatry. Curr Nutr Rep 9: 171-182, 2020.

71. Suez J,Zmora N,Zilberman-Schapira G, Mor U, Dori-Bachash M, Bashiardes S, Zur M, Regev-Lehavi D, Ben-Zeev Brik R, Federici S, et al: Post-Antibiotic Gut Mucosal Microbiome Reconstitution Is Impaired by Probiotics and Improved by Autologous FMT. Cell 174: 1406-1423.e16, 2018.

72. Dinić M, Pecikoza U, Djokić J, Stepanović-Petrović R, Milenković M, Stevanović M, Filipović N, Begović J, Golić N and Lukić J: Exopolysaccharide Produced by Probiotic Strain Lactobacillus paraplantarum BGCG11 Reduces Inflammatory Hyperalgesia in Rats. Front Pharmacol 9: 1, 2018.

73. Allen SJ, Martinez EG, Gregorio GV and Dans LF: Probiotics for treating acute infectious diarrhoea. Cochrane Database Syst Rev 2010: CD003048, 2010.

74. Zhong C, Qu C, Wang B, Liang S and Zeng B: Probiotics for Preventing and Treating Small Intestinal Bacterial Overgrowth: A Meta-Analysis and Systematic Review of Current Evidence. J Clin Gastroenterol 51: 300-311, 2017

75. Suez J, Zmora N, Segal E and Elinav E: The pros, cons, and many unknowns of probiotics. Nat Med 25: 716-729, 2019.

76. The Integrative Human Microbiome Project: The Integrative Human Microbiome Project. Nature 569: 641-648, 2019.

77. Poonyam P, Chotivitayatarakorn $P$ and Vilaichone RK: High Effective of 14-Day High-Dose PPI-Bismuth-Containing Quadruple Therapy with Probiotics Supplement for Helicobacter pylori Eradication: A Double Blinded-Randomized Placebo-Controlled Study. Asian Pac J Cancer Prev 20: 2859-2864, 2019.

78. Çekin AH, Şahintürk Y, Akbay Harmandar F, Uyar S, Yolcular BO and Çekin Y: Use of probiotics as an adjuvant to sequential $H$. pylori eradication therapy: Impact on eradication rates, treatment resistance, treatment-related side effects, and patient compliance. Turk J Gastroenterol 28: 3-11, 2017.

79. Pande C, Kumar A and Sarin SK: Addition of probiotics to norfloxacin does not improve efficacy in the prevention of spontaneous bacterial peritonitis: A double-blind placebo-controlled randomized-controlled trial. Eur J Gastroenterol Hepatol 24: 831-839, 2012.

80. Diepenhorst GM, van Ruler O, Besselink MG, van Santvoort HC, Wijnandts PR, Renooij W, Gouma DJ, Gooszen HG and Boermeester MA: Influence of prophylactic probiotics and selective decontamination on bacterial translocation in patients undergoing pancreatic surgery: A randomized controlled trial. Shock 35: 9-16, 2011.

This work is licensed under a Creative Commons Attribution-NonCommercial-NoDerivatives 4.0 International (CC BY-NC-ND 4.0) License. 